\title{
Psychosocial functioning in schizophrenia: are some symptoms or demographic characteristics predictors across the functioning domains?
}

This article was published in the following Dove Press journal:

Neuropsychiatric Disease and Treatment

29 September 2015

Number of times this article has been viewed

\author{
Sirijit Suttajit ${ }^{\prime}$ \\ Suwanna Arunpongpaisal ${ }^{2}$ \\ Manit Srisurapanont ${ }^{1}$ \\ Nuntika Thavichachart ${ }^{3}$ \\ Ronnachai Kongsakon ${ }^{4}$ \\ Sunanta Chantakarn ${ }^{5}$ \\ Vasu Chantarasak ${ }^{6}$ \\ Apichat Jariyavilas ${ }^{7}$ \\ Piyadit Jaroensook ${ }^{8}$ \\ Khanogwan Kittiwattanagul ${ }^{9}$ \\ Osot Nerapusee ${ }^{10}$ \\ 'Department of Psychiatry, Faculty \\ of Medicine, Chiang Mai University, \\ Chiang Mai, ${ }^{2}$ Department of \\ Psychiatry, Faculty of Medicine, \\ Khon Kaen University, Khon Kaen, \\ ${ }^{3}$ Department of Psychiatry, Faculty of \\ Medicine, Chulalongkorn University, \\ Bangkok, ${ }^{4}$ Department of Psychiatry, \\ Faculty of Medicine, Ramathibodi \\ Hospital, Bangkok, ${ }^{5}$ Department of \\ Psychiatry, Faculty of Medicine, Siriraj \\ Hospital, Bangkok, 'Somdetchaopraya \\ Institute of Psychiatry, Bangkok, \\ ${ }^{7}$ Srithanya Hospital, Bangkok, \\ ${ }^{8}$ Prasrimahabhodhi Hospital, Ubon \\ Ratchathani, ${ }^{9}$ Khon Kaen Rajanagarindra \\ Psychiatric Hospital, Khon Kaen, \\ 10Medical Affairs, Janssen-Cilag, \\ Bangkok, Thailand
}

Correspondence: Sirijit Suttajit Department of Psychiatry, Faculty of Medicine, Chiang Mai University, I I0 Intavaroros Road, Si Phum, Muang,

Chiang Mai 50200, Thailand

Tel +66 53945422

Fax +6653945426

Email sirijit.s@cmu.ac.th

\begin{abstract}
This study aimed to examine symptoms/demographic characteristics as predictors for psychosocial functioning among individuals with schizophrenia. The Personal and Social Performance (PSP) scale was used to assess psychosocial functioning. Other measures of interest included were the Clinical Global Impression, Severity scale, and the Marder's five-factor model of the Positive and Negative Syndrome Scale. This study included 199 participants with non-acute stage schizophrenia. Spearman correlation coefficients and stepwise multiple linear regression analyses were applied to determine the correlates and predictors of PSP domain/total scores. Younger age, earlier age of schizophrenia onset, severe illness, positive symptoms, negative symptoms, disorganized thought, hostility/excitement, and anxiety/depression were found to significantly correlate with poor functioning. Severe illness and negative symptoms are the main predictors of greater impairment of socially useful activities, personal and social relationships, and self-care. Further prospective studies in other settings, which would include an increased number of variables such as neurocognitive function and social support, are warranted.
\end{abstract}

Keywords: age, association, correlation, excitement, hostility, negative symptoms, severity

\section{Introduction}

Psychosocial functioning, including social activities, personal and social relationships, and self-care, is a key issue of schizophrenia. Together with psychotic symptoms, the Diagnostic and Statistical Manual of Mental Disorders, Fifth Edition (DSM-5) requires a deterioration (or failure to achieve adequate levels) of such functioning to make a diagnosis of schizophrenia. ${ }^{1}$ Some researchers suggested that functional outcomes of individuals with schizophrenia are needed to define therapeutic success, response to antipsychotic medications, and clinical effectiveness in real-world community practice..$^{2-4}$

Although psychosocial functional improvement is an ultimate goal for managing schizophrenia, it is not easily accomplished. Symptomatic remission does not always accompany functional improvement. ${ }^{5}$ Furthermore, effective interventions in the treatment of psychotic symptoms may not improve functioning. ${ }^{6-8}$ These lines of evidence may suggest that such psychosocial functioning may have a correlation with psychotic symptoms as well as several additional factors. Undergoing or using preventive or therapeutic interventions concurrently targeting these factors, may be a path to improve the functional outcomes.

Previous studies found that being of a younger age, unemployed, having a long duration of illness, a long length of current episode, suffering cognitive impairment, and severe negative symptoms are predictors of poor psychosocial functioning. ${ }^{9-11}$ Recently, a study from 
Italy explored the relationship between negative symptoms and functioning and found that avolition was the strongest predictor of the overall functioning, socially useful activities, personal and social relationships, and self-care. ${ }^{12}$ However, there has been conflicting evidence regarding the association between positive symptoms and psychosocial functioning. ${ }^{13-15}$

Most studies of psychosocial functioning were carried out in Western countries and they mainly focused on global functioning. Psychosocial functioning may be perceived differently from one culture to another, and its findings may not be comparable across cultures. ${ }^{16}$ In addition, it is not yet known whether the correlations related to global functioning are specific for or generalized across functioning domains. Examining the correlates of each functioning dimension would therefore give a clearer picture on the psychosocial functioning. In this study, the aim was to determine whether symptoms/demographic characteristics had a correlation with psychosocial functioning.

In addition, it was also important to examine symptoms/ demographic characteristics as predictors for domains of psychosocial functioning in individuals with schizophrenia. We hypothesized that a younger age, early age at onset, longer duration of illness, higher number of pervious psychiatric hospitalizations, more severe illness, and more psychotic symptoms were associated with lower psychosocial functioning.

\section{Methods}

This study is a part of the Paliperidone ER Functionality, Efficacy and Tolerability (PERFEcT) Study, a 6-month, open-label, multicenter, multi-country, prospective trial to explore the safety, efficacy, and functionality of paliperidone extended-release tablets. ${ }^{17}$ The current study included only the baseline data obtained from Thai participants. The study was approved by the Ethics Committee or the Institution Review Board of each participating site. Before participating in the study, each participant gave written, informed consent after the study details had been fully explained.

\section{Participants}

Participants included 199 adults with schizophrenia, diagnosed according to the Diagnostic and Statistical Manual of Mental Disorders, Fourth Edition criteria, from 12 sites across Thailand. ${ }^{18}$ Inclusion criteria were as follows: 1) being intolerant of medication, had shown a lack of compliance regarding medication, or having an inadequate response to adequate treatment of the previous antipsychotic medication; and 2) being in a non-acute stage, defined as having a Clinical Global Impression, Severity (CGI-S) score change $\leq 1$ in the past 4 weeks. Exclusion criteria included: 1) taking clozapine or long-acting antipsychotics in the past 3 months; 2) having a serious or unstable medical condition; 3 ) being diagnosed with substance dependence, except for caffeine or nicotine dependence, in the past 6 months; 4 ) having a history of tardive dyskinesia or neuroleptic malignant syndrome; 5) having a high risk of violence or suicide; and 6) pregnancy or breast feeding.

\section{Measures}

\section{Dependent variable}

\section{Psychosocial functioning}

The Personal and Social Performance (PSP) scale was used for assessing the psychosocial functioning of each participant. ${ }^{19}$ Four areas included in the PSP are socially useful activities (including work and study), personal and social relationships, self-care, and disturbing and aggressive behavior. The impairment of each domain is rated on a six-point basis, including absent (0), mild (1), moderate (2), marked (3), severe (4), and very severe (5). The higher domain score, therefore, indicates worse functioning in that particular area. The PSP total score (range: 1-100), which reflects the global functioning, is derived from the levels of impairment on the four domains. In contrast to the scoring system of its domains, the higher total PSP score suggests a higher level of functioning (71-100, mild functional difficulty; 31-70, varying degrees of disability; 1-30, minimal functioning needing intense support and/or supervision). ${ }^{3}$ The inter-rater reliability of the PSP scale, Thai version (ThaiPSP), was examined. ${ }^{20}$ The intraclass correlation coefficients ( $95 \%$ confidence intervals) of each domain and total scores were as follows: $0.63(0.28-0.96)$ for item 1 (socially useful activity); $0.75(0.42-0.98)$ for item 2 (personal and social relationships); 0.69 (0.35-0.97) for item 3 (self-care); 0.52 (0.17-0.94) for item 4 (disturbing and aggressive behavior); and $0.75(0.41-0.98)$ for the total score. ${ }^{20}$

\section{Independent variables \\ IIIness severity}

We used the CGI-S score for assessing the severity of illness. ${ }^{21}$ The CGI-S score provides an overall clinician-determined summary measure that takes into account all the information that is currently available. Its scores ranged from normal or no symptoms of illness (score of 1) to having the most extreme illness (score of 7). The rating is based on observed and reported symptoms, behavior, and functioning in the past 7 days.

\section{Symptoms}

The Positive and Negative Syndrome Scale (PANSS) was used for assessing psychopathology. The PANSS is a 30-item, 
clinician-rated instrument covering psychotic and other psychiatric symptoms commonly found in participants with schizophrenia. ${ }^{22,23}$ Each item is accompanied by a complete definition as well as detailed anchoring criteria for all seven rating points (1-7 for absent to extremely severe). The rating is also based on information pertaining to a specified period of the previous week. The PANSS total scores range from 30 to 210 . Although the PANSS scores originally included positive, negative, and general psychopathology scores, this study applied a five-factor model of the PANSS proposed by Marder et al. ${ }^{24}$ The latter model segregates the PANSS scores into positive symptoms, negative symptoms, disorganized thought, hostility/excitement, and anxiety/depression.

\section{Data analysis}

Because the PSP total score is subdivided into and described as ten equal intervals, ten-point intervals of the PSP total score (range: $1-10$ ) and the raw domain scores (range: 0-5) (ie, socially useful activity, personal and social relationships, self-care, and disturbing and aggressive behavior) were used for all analyses. ${ }^{19}$

Apart from sex (n, \%), all variables were described using means (standard deviations [SDs]). Spearman correlation coefficients were computed to test the associations between continuous demographic/clinical variables and the PSP domain/total scores. Independent $t$-tests were used to compare the PSP mean domain/total scores between groups.

Stepwise multiple linear regression analyses were applied to determine the predictors of PSP domain/total scores (for entry of $P<0.05$ ). The linear regression analysis was conducted for each of the four PSP domain scores. An adjusted $R^{2}$ was computed to evaluate the ratio of the sum of squares explained by a regression model. The coefficient values were used to quantify the strength of the associations. Statistical significance was defined as $P<0.05$. The IBM SPSS Statistics for Windows, version 22.0 (IBM Corporation, Armonk, NY, USA) was used for all analyses.

\section{Results}

This study included 199 individuals (104 males and 95 females) with schizophrenia participating from 12 sites across Thailand. Mean age and duration of illness (SDs) were 37.95 (12.09) and 10.48 (9.05) years, respectively. The mean PANSS total score (SD) was 57.80 (20.24). The mean total PSP score (SD) was 66.68 (17.51). For the PSP domain score, socially useful activity and personal and social relationships were more disturbed compared with self-care and disturbing and aggressive behavior (Table 1).
Table I Sociodemographic and clinical characteristics of the sample

\begin{tabular}{|c|c|}
\hline Variable & $N=199$ \\
\hline \multicolumn{2}{|l|}{ Sex, n (\%) } \\
\hline Male & $104(52.26)$ \\
\hline Female & $95(47.74)$ \\
\hline Age (years), mean (SD) & $37.95(12.09)$ \\
\hline Age at schizophrenia onset (years), mean (SD) & $26.99(9.50)$ \\
\hline Duration of illness (years), mean (SD) & $10.48(9.05)$ \\
\hline \multicolumn{2}{|l|}{ hospitalizations, mean (SD) } \\
\hline $\begin{array}{l}\text { Number of psychiatric hospitalizations } \\
\text { in the past } 6 \text { months, mean (SD) }\end{array}$ & in the past 6 months, mean (SD) \\
\hline CGI-S score, mean (SD) & $3.43(1.18)$ \\
\hline \multicolumn{2}{|l|}{ PANSS Marder score, mean (SD) } \\
\hline Total & $57.80(20.24)$ \\
\hline Positive symptom & $16.48(6.99)$ \\
\hline Negative symptom & $15.16(7.49)$ \\
\hline Disorganized thought & $12.42(4.77)$ \\
\hline Hostility/excitement & $6.27(2.86)$ \\
\hline Anxiety/depression & $7.48(3.09)$ \\
\hline \multicolumn{2}{|l|}{ PSP score, mean (SD) } \\
\hline Total & $66.68(|7.5|)$ \\
\hline Socially useful activity & $2.21(1.20)$ \\
\hline Personal and social relationships & $2.33(1.18)$ \\
\hline Self-care & $1.56(0.92)$ \\
\hline Disturbing and aggressive behavior & $1.73(0.97)$ \\
\hline
\end{tabular}

Abbreviations: CGI-S, Clinical Global Impression, Severity; PANSS, Positive and Negative Syndrome Scale; PSP, Personal and Social Performance; SD, standard deviation.

\section{Symptoms/demographic characteristics in correlation with the PSP scores}

Bivariate analyses found that age and age at schizophrenia onset were demographic data significantly associated with the PSP total, socially useful activities, and personal and social relationships scores. Age at schizophrenia onset was the only demographic data that was significantly related to the PSP self-care score. Together with the CGI-S score, the PANSS total and five subscale scores, including positive symptoms, negative symptoms, disorganized thought, hostility/excitement and anxiety/ depression, showed a significant positive correlation with the PSP total and all four domain scores. We did not find a significant association between duration of illness, number of previous psychiatric hospitalizations, number of psychiatric hospitalization in the past 6 months and the PSP scores (Table 2).

\section{Stepwise regression analysis}

All factors significantly associated with the PSP domain or total score $(P<0.05)$ in Table 1 were included in a stepwise regression model to determine which independent variables showed significant predictors for the PSP domain or total 
Table 2 Spearman correlations between symptoms/demographic characteristics and psychosocial functioning

\begin{tabular}{|c|c|c|c|c|c|}
\hline \multirow[t]{2}{*}{ Variable } & \multicolumn{5}{|c|}{ Personal and Social Performance score } \\
\hline & Socially useful activities & $\begin{array}{l}\text { Personal and social } \\
\text { relationships }\end{array}$ & Self-care & $\begin{array}{l}\text { Disturbing and } \\
\text { aggressive behavior }\end{array}$ & Total \\
\hline Age (years) & $-0.309 * * *$ & $-0.292 * * *$ & -0.082 & 0.019 & $0.22 I^{* *}$ \\
\hline Age at schizophrenia onset (years) & $-0.357 * * *$ & $-0.326 * * *$ & $-0.226 * *$ & -0.132 & $0.318 * * *$ \\
\hline Duration of illness (years) & -0.037 & -0.005 & 0.112 & 0.018 & $-0.04 I$ \\
\hline $\begin{array}{l}\text { Number of previous psychiatric } \\
\text { hospitalizations }\end{array}$ & -0.157 & -0.105 & -0.065 & 0.034 & -0.020 \\
\hline $\begin{array}{l}\text { Number of psychiatric hospitalizations } \\
\text { in the past } 6 \text { months }\end{array}$ & 0.155 & 0.092 & 0.164 & 0.165 & -0.103 \\
\hline CGI-S score & $0.537 * * *$ & $0.546 * * *$ & $0.476 * * *$ & $0.324 * * *$ & $-0.559 * * *$ \\
\hline PANSS Marder scores & & & & & \\
\hline Total & $0.444 * * *$ & $0.495 * * *$ & $0.459 * * *$ & $0.440 * * *$ & $-0.527 * * *$ \\
\hline Positive symptom & $0.363 * * *$ & $0.397 * * *$ & $0.369 * * *$ & $0.450 * * *$ & $-0.44 I^{* * *}$ \\
\hline Negative symptom & $0.414 * * *$ & $0.476 * * *$ & $0.479 * * *$ & $0.238 * * *$ & $-0.465^{* * *}$ \\
\hline Disorganized thought & $0.378 * * *$ & 0.426 *** & $0.430 * * *$ & $0.379 * * *$ & $-0.424 * * *$ \\
\hline Hostility/excitement & $0.311 * * *$ & $0.333 * * *$ & $0.220 * *$ & $0.515^{* * *}$ & $-0.389 * * *$ \\
\hline Anxiety/depression & $0.168 *$ & $0.161^{*}$ & 0.116 & $0.248 * * *$ & $-0.228 * * *$ \\
\hline
\end{tabular}

Note: Significant at $* * * P<0.001$ (two-tailed), $* * P<0.01$ (two-tailed), $* P<0.05$ (two-tailed).

Abbreviations: CGI-S, Clinical Global Impression, Severity; PANSS, Positive and Negative Syndrome Scale.

score in Table 2. The PANSS Marder negative symptom and the CGI-S scores were predictors for the PSP socially useful activities, personal and social relationships, and self-care scores. Age was a predictor of the PSP socially useful activities and personal and social relationships scores. The PANSS Marder hostility/excitement score was specifically a predictor of the PSP disturbing and aggressive behavior score. Together with the CGI scores and age at first schizophrenia onset, the PANSS Marder negative, hostility/excitement score, and disorganized thought scores were predictors for the PSP total score (adjusted $R^{2}=0.444$ ) (Table 3).

\section{Discussion}

In this study of Thai individuals with schizophrenia, severe illness and negative symptoms were general predictors of functional impairment. They were predictors of poor global functioning and poor functioning of most domains. A younger age was also a predictor of poor socially useful activities and personal and social relationships. Hostility/ excitement was a specific predictor of disturbing and aggressive behavior.

\section{Severity of illness and symptoms as predictors of psychosocial functioning}

A clinically relevant correlation between the PSP total and the CGI-S scores was found, not only in this study, but also in a psychometric study of the PSP. ${ }^{25}$ Moreover, the findings from this study support the notion that psychotic symptoms are common predictors of global psychosocial functioning. ${ }^{26-28}$

Similar to the findings of this study, the statistically significant correlation between negative symptoms and global functioning has been reported in many studies. ${ }^{15,29-32}$ Avolition was found to be the strongest predictor of the overall functioning, socially useful activities, personal and social relationships, and self-care. ${ }^{12}$ Moreover, severe negative symptoms are also predictors of poor performance in verbal fluency and lower IQ $, 33,34$ poor premorbid functioning, ${ }^{35}$ worse social adjustment, ${ }^{36}$ less possibility of living independently, ${ }^{37}$ and disability after a 1- or 3-year follow-up. ${ }^{26,38}$ Thus, the findings from this study underscored the importance of severe illness and negative symptoms in predicting functional impairment in all domains.

Previous studies, but not this study, found a significant correlation between positive symptoms and psychosocial functioning. ${ }^{13,39}$ Although our bivariate analyses found such a relationship, the correlation was not significant after adjustment for several variables in the regression models. The results were in line with a meta-analysis which reported that the association between positive symptoms and functioning was relatively weak compared with negative symptoms. ${ }^{15}$ Ventura et al explained that the individuals with schizophrenia might be able to compensate with positive symptoms such as ignoring the hallucination or delusion and maintain their functioning. ${ }^{15}$

While this study found a strong correlation between hostility/excitement and aggressive behavior, a previous 


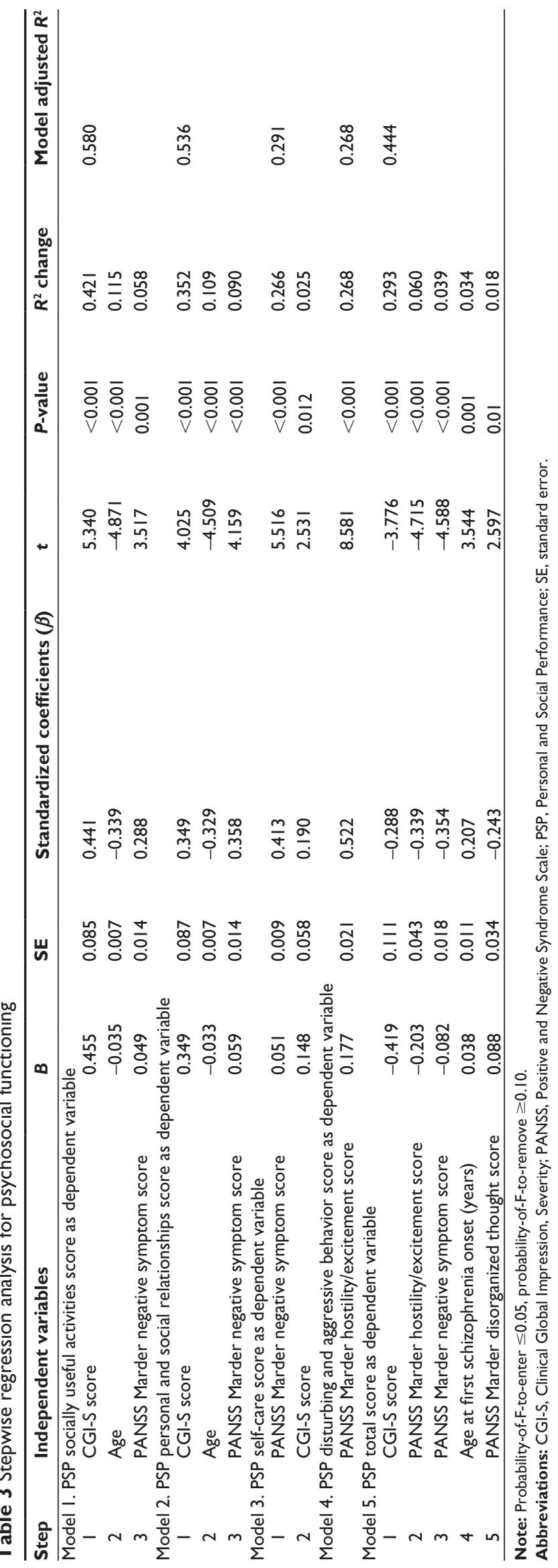

study found there was an association between positive symptoms and aggressive behavior. ${ }^{40}$ This discrepancy in findings might be explained by the fact that two out of four PANSS Marder hostility/excitement symptoms were the original PANSS positive symptoms (ie, excitement and hostility). ${ }^{24}$

\section{Demographic characteristics and psychosocial functioning}

The present findings suggest that young individuals with schizophrenia tend to suffer greater impairment regarding socially useful activities and personal and social relationships. These results are in line with a previous study of Schennach-Wolff et a ${ }^{10}$ but in contrast with some others. ${ }^{41,42}$ The dissimilar findings may be due to the differences in participants, measures, culture, and settings. Older adults in Thailand are more likely to live with their children, whereas younger adults tend to live alone. ${ }^{43}$ Less socialization of young adults with schizophrenia may cause more impaired functioning regarding socially useful activities and personal and social relationships. Furthermore, an early onset of schizophrenia usually has a correlation with poor premorbid adjustment, lower educational achievement, comorbidity, substance abuse, impulsivity, family history of schizophrenia, and more severe illness. ${ }^{44} 46$

\section{Strengths and limitations}

To the best of our knowledge, this is the first study examining the correlation between the specific domains of psychosocial functioning in Asia. It also emphasizes the role of symptoms and illness severity on the psychosocial functioning of individuals with schizophrenia. However, there are some limitations to this study. First, as a number of associations were analyzed in this study, a problem of multiple testing might have occurred. However, it is unlikely that this would explain the findings as most of the associations found in this study were highly significant at $P<0.001$. Second, as the participants included in this study were intolerant to medication, had a history of a lack of compliance to medication, or had an inadequate response to adequate treatment of antipsychotic medication, they might be more severely ill than general individuals with schizophrenia, and the findings from this study might lack generalization in transfer to other individuals with schizophrenia. However, the PANSS total mean score in this study was 58 , which is considered "mildly ill" according to the CGI-S score. ${ }^{47}$

Third, this study did not include several characteristics of the participants, in particular neurocognitive function. As cognitive ability is required for psychosocial skills, 
some studies found that they are crucial predictors of global psychosocial functioning and some of its domains. ${ }^{48,49}$ Fourth, the discrepancies between present and previous findings should be viewed with caution. Although several factors such as participants and methodology may play a role, the segregation of the PANSS scores into Marder's five-factor model in this study was also rarely used in previous studies.

Finally, this cross-sectional analysis cannot provide us direct evidence of causality. Indeed, potentially complex bidirectional interrelationships may underlie the observations. More severity of illness and symptoms might lead to more impaired psychosocial functioning, which, in turn, may worsen the severity of illness and symptoms. Further prospective studies are needed to determine causality.

Despite the aforementioned limitations, the results from this study demonstrate the specific associations between symptoms/demographic characteristics and the domains of functioning. Our analyses also indicate that individuals with schizophrenia, who have severe illness and negative symptoms, may need more comprehensive assessment of psychosocial functioning.

\section{Conclusion}

In conclusion, younger age, earlier age of schizophrenia onset, severe illness, positive symptoms, negative symptoms, disorganized thought, hostility/excitement, and anxiety/ depression were found to significantly correlate with poor functioning. Severe illness and negative symptoms are the main predictors of greater impairment of socially useful activities, personal and social relationships, and self-care. Further prospective studies in other settings which include more variables (eg, neurocognitive function, social support) are warranted.

\section{Acknowledgments}

Faculty of Medicine, Chiang Mai University supported the proof reading of the paper. The data of the study was part of the PERFECT study which was granted by JanssenCilag. However, the company did not involve in the study design, statistical analyses, nor manuscript preparation of this study.

\section{Disclosure}

SS received honoraria and/or consultancy fees from AstraZeneca, Janssen-Cilag, Lundbeck, and Thai-Otsuka. SA received honoraria and research grants from Thai-Otsuka and Servier. MS received honoraria, consultancy fees, research grants, and/or travel reimbursement from AstraZeneca,
Janssen-Cilag, Johnson \& Johnson, Lundbeck, Thai-Otsuka, Sanofi-Aventis, and Servier. SC received research grants from Janssen-Cilag. VC received honoraria and research grants from AstraZeneca, Dainippon Sumitomo Pharma, Eisai, Eli Lilly, Janssen-Cilag, Lundbeck, Organon, Pfizer, Thai-Otsuka, Sanofi-Aventis, and Servier. AJ received honoraria from AstraZeneca, Janssen-Cilag, Thai-Otsuka, and Servier. ON works for and owns stock of Johnson \& Johnson. NT, RK, PJ, and KK report no conflicts of interest in this work.

\section{References}

1. American Psychiatric Association. Diagnostic and Statistical Manual of Mental Disorders. 5th ed. Arlington (VA): American Psychiatric Association; 2013.

2. Juckel G, Morosini PL. The new approach: psychosocial functioning as a necessary outcome criterion for therapeutic success in schizophrenia. Curr Opin Psychiatry. 2008;21(6):630-639.

3. Nasrallah HA, Targum SD, Tandon R, McCombs JS, Ross R. Defining and measuring clinical effectiveness in the treatment of schizophrenia. Psychiatr Serv. 2005;56(3):273-282.

4. Suzuki T, Remington G, Mulsant BH, et al. Defining treatment-resistant schizophrenia and response to antipsychotics: a review and recommendation. Psychiatry Res. 2012;197(1-2):1-6.

5. Mueser KT. Cognitive functioning, social adjustment and long term outcome in schizophrenia. In: Sharma V, Harvey P, editors. Cognition in Schizophrenia: Impairments, Importance and Treatment Strategies. New York: Oxford University Press; 2000:157-177.

6. Meltzer HY, Bobo WV, Roy A, et al. A randomized, double-blind comparison of clozapine and high-dose olanzapine in treatment-resistant patients with schizophrenia. J Clin Psychiatry. 2008;69(2):274-285.

7. Berk M, Copolov D, Dean O, et al. N-acetyl cysteine as a glutathione precursor for schizophrenia - a double-blind, randomized, placebocontrolled trial. Biol Psychiatry. 2008;64(5):361-368.

8. Lane HY, Lin CH, Huang YJ, Liao CH, Chang YC, Tsai GE. A randomized, double-blind, placebo-controlled comparison study of sarcosine $(N$-methylglycine) and D-serine add-on treatment for schizophrenia. Int J Neuropsychopharmacol. 2010;13(4):451-460.

9. Haro JM, Novick D, Suarez D, Ochoa S, Roca M. Predictors of the course of illness in outpatients with schizophrenia: a prospective three year study. Prog Neuropsychopharmacol Biol Psychiatry. 2008;32(5): 1287-1292.

10. Schennach-Wolff R, Jager M, Seemuller F, et al. Defining and predicting functional outcome in schizophrenia and schizophrenia spectrum disorders. Schizophr Res. 2009;113(2-3):210-217.

11. Puig O, Penades R, Gasto C, Catalan R, Torres A, Salamero M. Verbal memory, negative symptomatology and prediction of psychosocial functioning in schizophrenia. Psychiatry Res. 2008;158(1):11-17.

12. Rocca P, Montemagni C, Zappia S, Pitera R, Sigaudo M, Bogetto F. Negative symptoms and everyday functioning in schizophrenia: a crosssectional study in a real world-setting. Psychiatry Res. 2014;218(3): 284-289.

13. Racenstein JM, Harrow M, Reed R, Martin E, Herbener E, Penn DL. The relationship between positive symptoms and instrumental work functioning in schizophrenia: a 10 year follow-up study. Schizophr Res. 2002;56(1-2):95-103.

14. Perivoliotis D, Granholm E, Patterson TL. Psychosocial functioning on the Independent Living Skills Survey in older outpatients with schizophrenia. Schizophr Res. 2004;69(2-3):307-316.

15. Ventura J, Hellemann GS, Thames AD, Koellner V, Nuechterlein KH. Symptoms as mediators of the relationship between neurocognition and functional outcome in schizophrenia: a meta-analysis. Schizophr Res. 2009;113(2-3):189-199. 
16. Mausbach BT, Moore R, Bowie C, Cardenas V, Patterson TL. A review of instruments for measuring functional recovery in those diagnosed with psychosis. Schizophr Bull. 2009;35(2):307-318.

17. Thavichachart N, Kongsakon R, Lo WT, et al. The psychopathological characteristics of treatment discontinuation group in 6-month treatment with paliperidone ER. Int J Clin Pract. 2012;66(10):969-975.

18. American Psychiatric Association. Diagnostic and Statistical Manual of Mental Disorders. 4th ed. Washington (DC): American Psychiatric Association; 1994.

19. Morosini PL, Magliano L, Brambilla L, Ugolini S, Pioli R. Development, reliability and acceptability of a new version of the DSM-IV Social and Occupational Functioning Assessment Scale (SOFAS) to assess routine social functioning. Acta Psychiatr Scand. 2000;101:323-329.

20. Srisurapanont M, Arunpongpaisal S, Chuntaruchikapong S, et al. Cross-cultural validation and inter-rater reliability of the Personal and Social Performance scale, Thai version. J Med Assoc Thai. 2008;91(10): 1603-1608.

21. Guy W. Clinical Global Impressions. In: ECDEU Assessment Manual for Psychopharmacology. Rockville (MD): US Department of Health, Education, and Welfare; 1976.

22. Kay SR, Fiszbein A, Opler LA. The positive and negative syndrome scale (PANSS) for schizophrenia. Schizophr Bull. 1987;13(2):261-276.

23. Kay SR, Opler LA, Lindenmayer JP. Reliability and validity of the positive and negative syndrome scale for schizophrenics. Psychiatry Res. 1988;23(1):99-110.

24. Marder SR, Davis JM, Chouinard G. The effects of risperidone on the five dimensions of schizophrenia derived by factor analysis: combined results of the North American trials. J Clin Psychiatry. 1997; 58(12):538-546.

25. Patrick DL, Burns T, Morosini P, et al. Reliability, validity and ability to detect change of the clinician-rated Personal and Social Performance scale in patients with acute symptoms of schizophrenia. Curr Med Res Opin. 2009;25(2):325-338.

26. Alptekin K, Erkoc S, Gogus AK, et al. Disability in schizophrenia: clinical correlates and prediction over 1-year follow-up. Psychiatry Res. 2005;135(2):103-111.

27. Gorna K, Jaracz K, Rybakowski F, Rybakowski J. Determinants of objective and subjective quality of life in first-time-admission schizophrenic patients in Poland: a longitudinal study. Qual Life Res. 2008;17(2):237-247.

28. Thirthalli J, Venkatesh BK, Kishorekumar KV, et al. Prospective comparison of course of disability in antipsychotic-treated and untreated schizophrenia patients. Acta Psychiatr Scand. 2009;119(3):209-217.

29. Kurtz MM. Symptoms versus neurocognitive skills as correlates of everyday functioning in severe mental illness. Expert Rev Neurother. 2006;6(1):47-56

30. Milev P, Ho BC, Arndt S, Andreasen NC. Predictive values of neurocognition and negative symptoms on functional outcome in schizophrenia: a longitudinal first-episode study with 7-year follow-up. Am J Psychiatry. 2005;162(3):495-506.

31. Shamsi S, Lau A, Lencz T, et al. Cognitive and symptomatic predictors of functional disability in schizophrenia. Schizophr Res. 2011;126(1-3): $257-264$
32. Rabinowitz J, Levine SZ, Garibaldi G, Bugarski-Kirola D, Berardo CG, Kapur S. Negative symptoms have greater impact on functioning than positive symptoms in schizophrenia: Analysis of CATIE data. Schizophr Res. 2012;137(1-3):147-150.

33. Carlsson R, Nyman H, Ganse G, Cullberg J. Neuropsychological functions predict 1- and 3-year outcome in first-episode psychosis. Acta Psychiatr Scand. 2006;113(2):102-111.

34. Howanitz E, Cicalese C, Harvey PD. Verbal fluency and psychiatric symptoms in geriatric schizophrenia. Schizophr Res. 2000;42(3): 167-169.

35. Addington J, Addington D. Premorbid functioning, cognitive functioning, symptoms and outcome in schizophrenia. J Psychiatry Neurosci. 1993;18(1):18-23.

36. Velligan DI, Mahurin RK, Diamond PL, Hazleton BC, Eckert SL, Miller AL. The functional significance of symptomatology and cognitive function in schizophrenia. Schizophr Res. 1997;25(1):21-31.

37. Hofer A, Baumgartner S, Edlinger M, et al. Patient outcomes in schizophrenia I: correlates with sociodemographic variables, psychopathology, and side effects. Eur Psychiatry. 2005;20(5-6):386-394.

38. Novick D, Haro JM, Suarez D, Vieta E, Naber D. Recovery in the outpatient setting: 36-month results from the Schizophrenia Outpatients Health Outcomes (SOHO) study. Schizophr Res. 2009;108(1-3):223-230.

39. Breier A, Schreiber JL, Dyer J, Pickar D. National Institute of Mental Health longitudinal study of chronic schizophrenia. Prognosis and predictors of outcome. Arch Gen Psychiatry. 1991;48(3):239-246.

40. Lincoln TM, Hodgins S. Is lack of insight associated with physically aggressive behavior among people with schizophrenia living in the community? J Nerv Ment Dis. 2008;196(1):62-66.

41. Dickerson F, Boronow JJ, Ringel N, Parente F. Social functioning and neurocognitive deficits in outpatients with schizophrenia: a 2-year follow-up. Schizophr Res. 1999;37(1):13-20.

42. Friedman JI, Harvey PD, Coleman T, et al. Six-year follow-up study of cognitive and functional status across the lifespan in schizophrenia: a comparison with Alzheimer's disease and normal aging. Am J Psychiatry. 2001;158(9):1441-1448.

43. Suttajit S, Punpuing S, Jirapramukpitak T, et al. Impairment, disability, social support and depression among older parents in rural Thailand. Psychol Med. 2010;40(10):1711-1721.

44. Kao YC, Liu YP. Effects of age of onset on clinical characteristics in schizophrenia spectrum disorders. BMC Psychiatry. 2010;10:63.

45. Ongur D, Lin L, Cohen BM. Clinical characteristics influencing age at onset in psychotic disorders. Compr Psychiatry. 2009;50(1):13-19.

46. Sham PC, Jones P, Russell A, et al. Age at onset, sex, and familial psychiatric morbidity in schizophrenia. Camberwell Collaborative Psychosis Study. Br J Psychiatry. 1994;165(4):466-473.

47. Leucht S, Kane JM, Kissling W, Hamann J, Etschel E, Engel RR. What does the PANSS mean? Schizophr Res. 2005;79(2-3):231-238.

48. Bowie CR, Depp C, McGrath JA, et al. Prediction of real-world functional disability in chronic mental disorders: a comparison of schizophrenia and bipolar disorder. Am J Psychiatry. 2010;167(9):1116-1124.

49. Bell M, Tsang HW, Greig TC, Bryson GJ. Neurocognition, social cognition, perceived social discomfort, and vocational outcomes in schizophrenia. Schizophr Bull. 2009;35(4):738-747.
Neuropsychiatric Disease and Treatment

\section{Publish your work in this journal}

Neuropsychiatric Disease and Treatment is an international, peerreviewed journal of clinical therapeutics and pharmacology focusing on concise rapid reporting of clinical or pre-clinical studies on a range of neuropsychiatric and neurological disorders. This journa is indexed on PubMed Central, the 'PsycINFO' database and CAS,

\section{Dovepress}

and is the official journal of The International Neuropsychiatric Association (INA). The manuscript management system is completely online and includes a very quick and fair peer-review system, which is all easy to use. Visit http://www.dovepress.com/testimonials.php to read real quotes from published authors. 